INSANITARY METIIODS IN TIIE HOME.

The limitations of time and circumstance do not permit any extended notice of the morbid developments observed among employés in atmospheres of daily domes. tic dust. In those places, however, in which medical scrutiny las been exercised longest and most closely the confident statement can be made that, while many contributory influences are involved, yet the pleurisies, pneumonias, bronchial catarrhs and cases of tonsillitis and influenza occurring among patrons and help find there a sufficient explanation in the local conditions, and undoubtedly these ailments prepare the way for the tuberculous infection that easily and commonly follows.

This infection is spolien of by some as a disease prone to originate in the poorer quarters of a city, but its prosence there, I am persuaded, is due to the fact that many wage-carncrs in clubs. hotels and like places are drawn from homes in such localities. Medical observation shows that after a time physical deterioration takes place among those employés most exposed to dust, and this is usually evidenced by coughs and other evidence of respiratery ailment.

That insidious peril from such cause can lurk in the often luxurious furnishings of places of the kind mentioned is hardly thought of by those most liable to be affected. but the contention that they are real and formidable sceding places for tuberculosis can, I believe, be established as truth on sufficient examination by any one so disposed.

\section{MODERN METHODS OF CLEANING.}

If so much be conceded, the question then recurs as to the nccessary measures of prevention, and it will readily be seen that these require the total banishment of broom and duster or any other implement or device by which dust is set afloat. If carpetings are to be retained, the adoption of mechanical appliances must follow, by the use of which no flying matter will be allowed to escape, this, if necessary, to be supplemented by the wiping of exposed surfaces and furniture with soft cloths.

The use of the vacuum or pneumatic method of cleaning in every hotel, club, office building, theater, church, school and business establishment should be made compulsory by law. This provision as a sanitary adjunct has become just as necessary a part of the house equipment as are those similarly supplied for heating, for ventilation, for fire protection or fire escape.

As to changes needed in ordinary methods in private houses to meet the demands of wholesome living as framed in the light of to-day, that is a domain concerning which others must speak, but it would appear that amendment in this direction is a very necessary part of the movement toward better health. This, however, is a phase of the problem that, first and last, lodges itself with the housekeepers of all civilized lands, and on them must rest the responsibility for its final and rightful determination.

The city mentioned in which are situated the clubs, etc., whose delinquencies in a certain respect have been pointed out, is said to be the most representative of all American municipalities, in the sense that the different races and nationalities composing its population are more evenly blended than in any other place of nearly the same size; hence, sanitary faults existing there would probably be found present in other cities also. The indoor dust problem, thercfore, becomes one of more than local importance and must concern peoples and populations everywhere who may be liable to fall under the influence of similar unwholesome conditions, becoming in fact national, if not international, in scope.

It has been written of ancient peoples that, in times of great public stress or sore calamity, they would scek the altars of their respective religions and anxionsly demand of the priests, wherein they had offended the gods, in order that, by suitable sacrifice or offerings.. atonement might be made for transgressions, and the offended deity be thus placated and no longer visit on them his wrath. And the people of to-day, here and elsewhere, may well ask wherein they have offended when it is remembered that one-tenth of all deaths occurring in civilized lands are due to tuberculosis, and bestir themselves to the work of expiation for manifold transgressions of the plain laws of health which entail such a heavy punishment.

\section{SUMMARY.}

1. Efforts toward the eradication of human tuberculosis will fail which do not take full account of household dust as a factor in the dissemination of that disease.

2. Scientific tests have shown that the sceds of pulmonary tuberculosis, harbored within doors in the dried state, are capable of retaining their effective vitality for prolonged periods of time.

3. Any method or procedure emplored in inhabited buildings which causes dust to be disseminated must be considered as tending to spread the seeds of consumption.

4. Hotcls, clubs, theaters, office buildings, schools, churches and business establishments generally should be required by law to introduce and operate dustless methods of cleaning; this nart of their mechanical cquipment being as nccessary as provicion similarly made for warming, ventilation and for fire protection and fire escape. The cmployment of dustless methods in private residences is ureed as being equally imperative for the control and suppression of all forms of tuberculous disease.

\section{THE VALUE OF SULPHATES IN CARBOLIC- ACID POISONING.*}

TORAld solimann, M.D., and EDGaR D. BRoWn, Pir.D. .CLEVEland, OHIO.

\author{
MISTORICAL DATA.
}

The treatment of phenol poisoning by sulphates dates from the obscrvation of Baumann, ${ }^{1}$ in $18^{N}(j)$, that a considerable proportion of the phenol is excreted in the urine as the practically harmless phenol-sulphonic (sulphocarbolic) acid, $\mathrm{C}_{6} \mathrm{H}_{4}(\mathrm{OH}) \mathrm{SO}_{3} \mathrm{H}$, or, rather, as the salts of this acid with the urine bases. Baumann suggested that this constitutes a natural mechanism for the disintoxication of phenol. Since only a part of the phenol is excreted in this form, it seems reasonable to suppose that the quantity of sulphate at the disposal of the body was not sufficient to combine with all the phenol, and that the efficiency of the mechanism could, therefore, be increased by the administration of sulphates. Baumann tested this suggestion on two dogs, painting the phenol on the skin. The result was in agreement with the theory, although it was not sufficiently rigorous to be conclusive. Sonnenburg, ${ }^{2}$ in 1878 , reported favorably

* This is the second of a series of studies on the treatment of phenol poisoning. The first paper, on the value of alcohol, by T. W. Clarke and E. D. Brown, appeared in THE Jourval, March 17, 1906. * From the Pharmacological Laboratory of Western Reserve Lniversity.

1. Arch. f. d. gesam. Physlol., 1876, xili, 285.

2. Deutscbe Ztschr. f. Chir., 1878, 1x, 356. 
on the clinical use of sulphates in the subacute poisoning resulting from the external application of the phenol.

The next work was done by Cerna $^{3}$ in 1879 and by Cafrawy in 1881. Both experimenters worked on animals and formed a favorable judgment, but Tauber ${ }^{5}$ rejects their results as absolutely valueless because of errors of technic and interpretation. Tauber, in 1895, published the first reliable experimental data on the reputed antagonism. He injected a just fatal dose of phenol subcutaneously into rabbits, following this by oral, subcutaneous or intravenous injection of sodium sulphate. His three experiments were purely negative: the animals died in from fifteen minutes to one hour, just as they would have done without treatment. He suggests in explanation that the phenol does not combine in the body with sulphates, but only with sulphur in lower stages of oxidation; and in support quotes a somewhat more favorable effect from the administration of sulphites-too small, however, to be of any therapeutic significance.

The subject was taken up independently, at about the same time (1894), by Marfori, ${ }^{\mathbf{B}}$ who worked with different methods and arrived at different conclusions. Marfori used dogs and injected the solutions intravenously, but so slowly that no acute effects were produced until death resulted, the injections lasting from four and one-half to nine hours. He determined in this way the total lethal dose and the amount of combined sulphate excreted in the urine; the latter as a measure of the amount of phenol which had entered into the harmless combination. Into ten of his animals he injected phenol alone, into seven a mixture of phenol and ammonium sulphate. His results showed that when phenol alone is injected under these conditions from one-fourth to one-half is excreted as the sulphate. When ammonium sulphate is injected at the same time, more phenol can generally be injected and a greater amount (up to three times as much) is excreted as the sulphonate. The tolerance, however, is limited; indeed, two of his animals died with practically the normal fatal dose; in no ease was anything like the total injected quantity of phenol excreted as the sulphonate.

The conclusions of Tauber and Marfori, however they differ in other respects, agree in assigning a very small value, if any, to the sulphate treatment. This agreement, however, seems to have been less impressive than the differences, for we find that many of the recent textbooks give prominent favorable mention to the sulphate treatment. We also started our experiments with a favorable bias, based on the superficial impressions of some class experiments and on some reported clinical results.

\section{SUMMART OF THE AUTHOL'S' RESULTS.}

In view of the prevailing contradictory opinions, we shall detail our experiments rather fully; but for those who are not interested in these details we may premise the conclusion that sodium sulphate, however administered, is not a chemical antidote in acute phenol poisoning. This conclusion follows very clearly from our results, namely :

1. Chemical combination between phenol and sulphate does not occur outside of the body, neither in neutral nor in weakly acid nor in weakly alkaline solution. This

3. Medical Times, Fhiladelphia, 1879, ix, 592.

4. Thesis, Paris, 1881.

5. Arch. f. exper. Path. u. Pharm., 1895, rxxvi, 197.

6. Arch. Ital. de Biol., 1894, xxil, 204. excludes at once all possibility of chemical combination in the alimentary canal or in the blood.

2 . The blood pressure and convulsive effects of phenol are not modified in the slightest degree by intravenous injection of liberal quantities of sodium sulphate under any of the following conditions:

(a) When phenol, even in sublethal doses, is introduced into the stomach, and is followed within fifteen minutes by intravenous sulphate injection.

(b) When sublethal doses of phenol are injected intravenously, and followed promptly by the sulphate.

(c) When sublethal doses of phenol are injected intravenously after the sulphate injection.

(d) When an incubated mixture of phenol, sodium sulphate and sodium bicarbonate is compared with a solution of phenol in sodium chlorid solution.

(e) When the sulphate is injected immediately after cardiac stoppage from lethal doses of phenol.

DETAILS OF THE RESULTS.

To answer the question whether or not phenol sulphonate is formed outside of the body under the conditions which obtain in poisoning, the mixtures were allowed to stand for the specified time, the free sulphate was precipitated with barium chlorid, the mixture filtered, and any combined sulphate sought for by boiling with hydrochloric acid and adding barium chlorid. The result was uniformly negative. The following mixtures were tried:

Five c.c. of 95 per cent. phenol plus 95 c.c. of 1.9 per cent. $\mathrm{Na}_{2} \mathrm{SO}_{4}$, standing 5 minutes. The same mixture, standing 24 hours.

Five c.c. of 95 per cent. phenol plus 95 c.c. of 2 per cent. $\mathrm{Na}_{2} \mathrm{SO}_{4}$ plus 0.4 per cent. $\mathrm{HCl}$, standing 24 hours.

One gm. phenol, $4 \mathrm{gm}$. $\mathrm{Na}_{2} \mathrm{SO}_{4}+10 \mathrm{H}_{2} \mathrm{O}, 0.03 \mathrm{gm}$. $\mathrm{NaHCO}_{3}$, 100 c.c. water, incubated for 24 hours at $38^{\circ} \mathrm{C}$, then 6 days at room temperature.

Animal Experiments.-The results of the chemical experiments left open the possibility that the phenol and sulphate might combine in the body as a result of ferment activity, or within the cells. Animal experiments were necessary to decide this question. These we attempted to shape so as to imitate as closely as possible the most favorable conditions for treatment in acute poisoning. In view of the rapid absorption of phenol, the method of Marfori, extending the injection over many hours, appeared to us ill adapted to answer the question. We, therefore, introduced the poison and antidote rapidly. In investigating antagonism, one may either concentrate the attention of the sum total of the deleterious effects culminating in death, $i$. e., one may determine the minimum lethal dose, or, secondly, one may select one or several easily observable phenomena produced by sublethal doses. The former method is generally the more satisfactory and has been adopted by our predecessors. It is unsatisfactory, however, in the case of phenol, since the fatal dose per kilo of bisty weight varies, according to Marfori, with the size of the animal, and, according to our observations, acute death with intravenous injection depends altogether on the rapidity with which the drug is introduced. The blood pressure phenomena and the convulsive twitchings, particularly the former, are, on the other hand, perfectly satisfactory.

The experiments were made on anesthetized dogs by the usual technic. The blood prossure tracings were taken from the carotid artery by a mercurial manometer. The intravenous injections were made into the cardiac end of the femoral vein. The phenol when 
administered by stomach tube was undiluted, but was washed down with a small quantity of water; when injected intravenously it was reduced to a 1 per cent. or 0.5 per cent. solution with 0.9 per cent. sodium chlorid. The latter was also used for control injection. The sodium sulphate solution contained 1.9 per cent. of the anhydrous salt.

\section{PHENOL BY STOMACH TUBE, SULPHATE INTRAVENOUSLY.}

Dog. 11, tracings 30 and 31: Vagi cut, 1 c.c. of 95 per cent. phenol per kg. of body weight into stomach. Blood pressure fell immediately, descending $78 \mathrm{~mm}$. of $\mathrm{Hg}$ (from 138 to 60) in 4 minutes. Remained at this level. Fourteen minutes after phenol, injected 15 c.c. of sodium chlorid solution per $\mathrm{kg}$. into femoral vein. Excursions slightly increased, mean pressure unaltered. Between 15 and 25 minutes after the phenol, injected 25 c.c. of sulphate solution per $\mathrm{kg}$. Slight temporary increase of excursions, mean pressure not affected up to 75 minutes, when the experiment was stopped.

Dog 13, tracings 34 and 35: One c.c. of 95 per cent. phenol and 1 c.c. of alcohol per $\mathrm{kg}$. by stomach tube. Blood pressure fell $61 \mathrm{~mm}$. in 6 minutes (from 126 to 65 ). Three intravenous injections of $\mathrm{NaCl}$, each of 12 c.c. per kg., at one-minute intervals, the first 6 minutes after the phenol. The blood pressure showed a very slight rise $(14 \mathrm{~mm}$.), each injection caused some increase of the excursions. Four intravenous injections of $\mathrm{Na}_{2} \mathrm{SO}_{4}$, each of 12 c.c. per kg., the first 13 minutes after the phenol, the second 16 minutes, the third 20 minutes, the fourth 55 minutes. Each injection caused a slight rise of pressure $(6$ to $10 \mathrm{~mm}$.) which passed off within a minute after the injection. The mean pressure was $60 \mathrm{~mm}$. at the end of the experiment, 58 minutes after the injections of the phenol.

Dog 14, tracing 36: Phenol and alcohol, each 0.5 c.c. per $\mathrm{kg}$. by stomach. In 7 minutes the pressure had fallen $34 \mathrm{~mm}$. (from 108 to 74 ). Intravenous $\mathrm{NaCl}, 11$ c.c. per $\mathrm{kg}$., $11 \mathrm{~min}$ utes after the phenol. No effect. Two injections of $\mathrm{Na}_{2} \mathrm{SO}_{4}$, each 11 c.c. per $\mathrm{kg}$., the first 14 , the second 15 minutes after the phenol; no effect. The pressure continued to decrease gradually, being $60 \mathrm{~mm}$. at the end of 30 minutes.

These experiments presented the most ideal conditions for the sulphate treatment: Intravenous administration of the sulphate in liberal quantity (from 22 to 48 c.c. of 1.9 per cent. per kg.) within a short time (13 to 15 minutes) after the phenol, the quantity of the latter but slightly exceeding the fatal dose in two of the dogs, and being distinctly less in the third. Notwithstanding these favorable conditions, the immediate effect of the sulphate is practically negative and does not differ in any respect from that of the sodium chlorid by which it was preceded. Nor was there any evidence of any later benefit, for the blood pressure showed no tendency to recover in from 30 to 75 minutes, whereas, after gastric lavage, Clarke and Brown noticed improvement, generally in from 15 to 34 minutes.

\section{INTRAVENOUS INJECTTON OF SUBLETHAL DOSES OF PHENOL FOLLOWED BY SULPHATE.}

Dog 1, tracing 2: Five injections of phenol, each $0.01 \mathrm{gm}$. per kg., as 1 per cent. solution in 10 per cent. alcohol at oneminute intervals (total, $0.05 \mathrm{gm}$. per $\mathrm{kg}$.). Each injection caused a slight fall (about $15 \mathrm{~mm}$.). There was complete recovery after the first 2 injections, then this was incomplete, so that the average pressure had fallen $11 \mathrm{~mm}$. (from 83 to 72) after the last injection. Four intravenous injections of 1.25 c.c. per $\mathrm{kg}$. of the sulphate solution, given at short inter. vals, had no effect to the end of the experiment.

Dog 4, tracings 16 and 17: $0.09 \mathrm{gm}$. per $\mathrm{kg}$. of phenol as 1 per cent. solution, distributed over 4 injections. Both vagi were divided. The pressure recovered to $90 \mathrm{~mm}$. (original pressure, $98 \mathrm{~mm}$.). Twitchings were present after the first injection $(0.05 \mathrm{gm}$. per $\mathrm{kg}$.). Five injections of sulphate, each 5 c.c. per kg. (total, 25 c.c. per kg.) were given within 10 minutes. The pressure rose during the injection, but at the end returned to the previous level. Marked convulsive movements were noted.

Tracing 18: $0.05 \mathrm{gm}$. per $\mathrm{kg}$. of phenol as 1 per cent. solution. The pressure fell at once $25 \mathrm{~mm}$. Within one minute 10 c.c. per $\mathrm{kg}$. of the sulphate was injected, followed by 5 c.c. per $\mathrm{kg}$. in one minute and again in 6 minutes. The blood pressure recovered steadily, just as it would do without the sulphate, the injections making no impression on the curve.

Dog 15, tracing 38: $0.025 \mathrm{gm}$. of phenol per $\mathrm{kg}$. as $1 / 2$ per cent. solution. The pressure fell at once $50 \mathrm{~mm}$. (from 140 to $90)$, then started to recover. The injection of 15.6 of sulphate solution per $\mathrm{kg}$. produced no impression on the curve. Twitching was observed after the first injection. The pressure returned to the original in 7 minutes.

Dog 17, tracing 44: $0.01 \mathrm{gm}$. of phenol as 1 per cent. solution. Pressure fell $25 \mathrm{~mm}$. and recovered. Eleven minutes later, second injection of phenol, $0.05 \mathrm{gm}$. per $\mathrm{kg}$., fell $30 \mathrm{~mm}$. and recovered. Twenty c.c. of $\mathrm{NaCl}$ solution per $\mathrm{kg}$. caused no change in the curve. Within 30 seconds after the second phenol injection, marked muscular twitching appeared, ceasing again in less than 5 minutes. A third phenol injection, 0.05 gm. per kg., caused marked twitchings in 30 seconds and 40 $\mathrm{mm}$. fall of pressure (from 120 to 80 ). One and one-half minutes after the phenol, when the pressure had already begun to recover, injected 20 c.c. per $\mathrm{kg}$. of sulphate solution. This did not affect the curve of mean pressure, although the excursions were considerably strengthened and slowed. The twitchings practically ceased within 5 minutes, i. e., about the same time as without aulphate.

These experiments bear out the conclusions derived from the gastric administration: The sulphate has not the slightest influence on the recovery of the blood pressure after sublethal doses of phenol.

intrayenous inJection OF PHENOL AFTER SODIUM SUlPhate.

Dog 4, tracing 18: The animal received $0.09 \mathrm{gm}$. per $\mathrm{kg}$. of phenol in divided doses, then 25 c.c. per $\mathrm{kg}$. of sulphate as described above. The blood pressure returned to the original level. About 45 minutes after the sulphate, injected $0.05 \mathrm{gm}$. per kg. of phenol as 1 per cent. solution; the pressure fell 25 mm. Sulphate was again injected, 20 c.c. per $\mathrm{kg}$. When the pressure had recovered, 5 minutes after the sulphate, injected $0.05 \mathrm{gm}$. per $\mathrm{kg}$. of phenol, usual fall of pressure.

Dog 15, tracing 39: The animal received $0.02 \tilde{\mathrm{gm}}$. per $\mathrm{kg}$. of phenol, followed by 15.6 c.c. per $\mathrm{kg}$. of sulphate solution. The pressure fell $50 \mathrm{~mm}$. and returned to the original level Eleven minutes after the sulphate, injected phenol $0.025 \mathrm{gm}$. per $\mathrm{kg}$. The fall of pressure was $60 \mathrm{~mm}$., i. e., somewhat greater than the fall produced by the same dose of phenol before the sulphate injection.

Dog 17, tracing 45: The animal received 0.01 and $11 \mathrm{~min}$ utes later, $0.05 \mathrm{gm}$. per $\mathrm{kg}$. of phenol, and then a third injection of $0.05 \mathrm{gm}$. per $\mathrm{kg}$., followed by 20 c.c. per $\mathrm{kg}$. of sulphate solution. The first injection caused a fall of $25 \mathrm{~mm}$., the second of $30 \mathrm{~mm}$., the third of $40 \mathrm{~mm}$., with complete recovery of pressure in each instance. Twenty-six minutes after the sulphate, injected phenol, $0.05 \mathrm{gm}$. per $\mathrm{kg}$; the pressure fell $45 \mathrm{~mm}$. The convulsions occur as before the sulphate injection.

These experiments show that the presence of sulphate in the blood, before the phenol is injected, do not mitigate in the slightest degree the effects of phenol on the circulation, nor its convulsant action.

\section{COMPPARISON OF THE PHENOL EFFECTS IN A MEDIUM OF SODIUM CHLORID AND ALKALINIZED SODIUM SULPHATE.}

To secure the closest possible approximation of physio. logic conditions to the requirements for combination of phenol and sulphate, a mixture of $10 \mathrm{gm}$. of phenol, 40 gm. of crystallized $\mathrm{Na}_{2} \mathrm{SO}_{4}, 0.3 \mathrm{gm}$. of $\mathrm{NaHCO}_{3}$ and 1,000 c.c. of water was incubated at $38^{\circ} \mathrm{C}$. for 25 hours, then set aside at room temperature for another day. In the first experiment this solution was injected alone, 
in the second alternately with a solution of phenol in 0.9 per cent. $\mathrm{NaCl}$, containing the same quantity of phenol (1 per cent.).

Dog 28, tracing 67: Vagi divided. Blood pressure $90 \mathrm{~mm}$. Injected $0.03 \mathrm{gm}$. of phenol per $\mathrm{kg}$. in alkaline sulphate medium. Pressure fell $30 \mathrm{~mm}$., recovered promptly and rose to $95 \mathrm{~mm}$. Six minutes after the first dose, injected $0.02 \mathrm{gm}$. phenol per $\mathrm{kg}$. in alkaline sulphate; fell $40 \mathrm{~mm}$. and in 15 minutes the pressure had returned to $90 \mathrm{~mm}$. Thirty minutes after the second dose, injected $0.05 \mathrm{gm}$. per $\mathrm{kg}$. in the sulphate solution; fell 70 $\mathrm{mm}$. with complete recovery. In 33 minutes the pressure had risen to $105 \mathrm{~mm}$. Thirty-seven minutes after the third dose, injected $0.075 \mathrm{gm}$. per $\mathrm{kg}$. in the sulphate solution. The pressure fell to $20 \mathrm{~mm}$., respiration and heart beat ceased.

Dog 29, tracings 68 and 69: Vagi divided. Blood pressure $135 \mathrm{~mm}$. Injected $0.025 \mathrm{gm}$. of phenol per $\mathrm{kg}$. in $\mathrm{NaCl}$, intravenously; pressure fell $43 \mathrm{~mm}$. and recovered to $110 \mathrm{~mm}$. Fourteen minutes after the first dose, injected $0.025 \mathrm{gm}$. per $\mathrm{kg}$. of phenol in alkaline sulphate; pressure fell $48 \mathrm{~mm}$. and recovered to $111 \mathrm{~mm}$. Seventeen minutes after the second dose, injected $0.05 \mathrm{gm}$. per $\mathrm{kg}$. of phenol in the chlorid; pressure fell $51 \mathrm{~mm}$. and recovered to $110 \mathrm{~mm}$. Fifty minutes after the third dose, injected $0.05 \mathrm{gm}$. per $\mathrm{kg}$. of phenol in alkaline sulphate; pressure fell $50 \mathrm{~mm}$. and recovered to 110 mm.

These results show that an incubated mixture of phenol with sodium sulphate and alkali produce precisely the same effects as a simple solution of phenol with sodium chlorid, quantitatively as well as qualitatively.

SULPHATE INJECTION AFTER LETHAL DOSES OF PHENOI.

Dog 4, tracing 18: The animal received $0.09 \mathrm{gm}$. of phenol per kg. intravenously, divided into 4 doses; the pressure recovered. In an hour and a half injected $0.15 \mathrm{gm}$. per $\mathrm{kg}$.; the pressure fell to $30 \mathrm{~mm}$., the heart beats were weak and slow; marked convulsions. Two minutes after the phenol injected 20 c.c. per $\mathrm{kg}$. of sulphate solution; no improvement.

Dog 15, tracing 39: The animal received intravenously 0.025 gm. of phenol per kg.; the pressure recovered. Thirteen minutes after this first administration again injected phenol intravenously, $0.025 \mathrm{gm}$. per $\mathrm{kg}$.; the pressure fell $60 \mathrm{~mm}$. (from 127 to 65). As soon as it showed a tendency to recover, i. e., within one minute, again injected phenol, $0.0125 \mathrm{gm}$. per $\mathrm{kg}$. Seven such doses were injected in 5 minutes, resulting in a very gradual fall of the mean pressure of $18 \mathrm{~mm}$. (from 65 to 47). Three injections of phenol were now made, 30 seconds apart, the first of 0.025 , the second and third, each, of 0.04 gm. per kg. These caused a further gradual fall of $16 \mathrm{~mm}$. (from 47 to $31 \mathrm{~mm}$.) when the heart suddenly stopped. Sulphate was injected at once, 15 c.c. of the solution per kg., and this was followed in one minute by artificial respiration and vigorous cardiac massage. Two further injections of the sulphate solution, of the same dose, were given within 5 minutes. The animal did not revive.

Dog 16, tracing 42: In the course of 20 minutes this animal received, intravenously, 3 injections of phenol, each of $0.025 \mathrm{gm}$. per $\mathrm{kg}$. The blood pressure returned to the original (125 $\mathrm{mm}$.). Half an hour after the last dose a second series of phenol injections were started, 5 doses of $0.025 \mathrm{gm}$. per $\mathrm{kg}$. being given within 30 minutes. Ten minutes after the last injection the pressure stood at $85 \mathrm{~mm}$., a permanent fall of 40 $\mathrm{mm}$. The third series of injections was started, the injections being repeated at minute intervals, or as soon as the pressure showed a tendency to rise. The first injection, $0.0275 \mathrm{gm}$. per $\mathrm{kg}$., lowered the pressure $45 \mathrm{~mm}$. The second, third and fourth injections $(0.0275,0.0275,0.015 \mathrm{gm}$. per $\mathrm{kg}$.) caused a gradual further fall of $15 \mathrm{~mm}$ (to $25 \mathrm{~mm}$.). Within 8 minutes, the pressure had returned to $40 \mathrm{~mm}$. An injection of $0.05 \mathrm{gm}$. per $\mathrm{kg}$. caused it to fall again to $25 \mathrm{~mm}$. Another dose of the same size, injected within one minute, lowered the pressure to $18 \mathrm{~mm}$., at which it remained for 5 minutes, when the last injection of $0.05 \mathrm{gm}$. per $\mathrm{kg}$. was made. This caused almost immediate sudden stoppage of the heart. Artificial respira- tion, vigorous cardiac massage and the injection of 33 c.c. per kg. of sulphate solution caused resuscitation of the heart, but the respiration remained paralyzed.

Dog 17, tracing 45: The animal had received intravenously 3 doses of phenol of $0.01,0.05,0.05 \mathrm{gm}$. per $\mathrm{kg}$., distributed over 30 minutes. Half an hour after the last dose the pressure was rather higher than at the start (134 mm.). A fourth dose of phenol, $0.05 \mathrm{gm}$. per $\mathrm{kg}$., produced the usual fall of pressure (45 mm.) followed by recovery of the pressure. During the recovery, however, there was strong vagus stimulation, and 4 minutes after the injection the heart stopped suddenly, evidently due to excessive vagus stimulation. Immediately injected 25 c.c. of sulphate solution, practiced cardiac massage; no recovery.

The results show that sulphate injection after stoppage of the heart is no more effective than sodium chlorid injection.

\section{DISCUSSION}

Our results as sketched in the preceding summary are conclusive in showing that sulphate injections do not influence the course of acute phenol poisoning appreciably under the conditions of our experiments. When the phenol was injected intravenously, the animals promptly recovered from the severe fall of blood pressure and from the convulsive twitchings, but the recovery was equally prompt without any treatment. When the clinical conditions were imitated by giving larger doses of phenol by stomach and the sulphate intravenously, the latter caused no marked permanent improvement, no tendency to recovery. There was in some cases an increase of the cardiac excursions and sometimes a slight temporary improvement of blood pressure, but these effects were insignificant in degree and duration and were obtained equally by corresponding injections of sodium chlorid; they were, therefore, expressions of saline stimulation and not of chemical antagonism.

We are forced to accept the same explanation for certain clinical cases which have been communicated to us informally from various sources. Of these we have no exact records, but they appear to agree in the essentials. In advanced cases of phenol poisoning the intravenous or subcutaneous sulphate injections produced no effect. In less severe cases, on the other hand, the improvement seemed very striking, the patient often recovering consciousness while the injection was being made. The very success in these instances excludes the possibility of a chemical combination, for all investigators agree that the combination of the phenol could not be effected in so short a time. The improvement must have been due to saline stimulation.

Our negative results agree with those of Tauber, who also worked with acutely fatal doses; their apparent contradiction to the conclusions of Marfori is doubtless to be referred to the slower introduction of the poison adopted by this investigator. He succeeded in demoñstrating some increase of the combined phenol in the urine; but, as he emphasizes, this combination occurs so slowly that he was obliged to inject the phenol so gradually that it produced no symptoms for from 6 to 9 hours. This resembles the conditions of chronic phenol poisoning rather than those of the acute form, in which the symptoms set in with startling rapidity, and which practically runs its course, as a rule, within two or three hours

The compilation of Clarke shows that, with gastric lavage, six out of seven patients had recovered consciousness within this time. With this in mind, it appears quite useless to administer an antidote which be- 
comes effective only after four hours or later. In a limited number of cases, death occurs from phenol after a longer period, with intervening partial recovery; but, considering the usual rapid course of the poisoning, we are inclined to refer this to indirect effects of the acute action, such as the local effects or the profound nervous shock, rather than to a delayed action of the retained phenol. Even in these cases, therefore, we would expect little benefit from the chemic antagonism. Whether or not it is of any use in genuine chronic poisoning, our experiments do not answer.

On the other hand, we would emphasize the fact that the saline stimulation from intravenous or subcutaneous injections appears to be of distinct value clinically, although it was not very striking in our animal experiments. Since this is a harmless procedure, it deserves trial in conjunction with the lavage. The sulphate has generally been used in the quantity of from 0.5 to 1 liter of a solution containing 2.3 per cent. of the anhydrous or 4.6 per cent. of the crystalline salt, employing the usual technic of saline injection. We know of no data showing whether it possesses any advantage over ordinary saline (sodium chlorid) solution. The administration of sodium or magnesium sulphate by the alimentary canal would, of course, be useless for this purpose, especially as these salts are scarcely at all absorbed.

\section{SIMPLE ULCER OF THE BLADDER} GEORGE WALKER, M.D.

Associate in Surgery, Johns Hopkins University. BALTIMORE.

Relatively few well-described instances of simple ulcer of the bladder have been recorded, but these are sufficient to establish the existence of such a condition.

It may be defined as a single non-inflammatory ulcer located in the mucous membrane of the bladder, which occasionally penetrates the entire wall.

The condition is probably caused by a local disturbance in, or complete blocking of, the terminal arteries or by an interference with the trophic nerves. Infection of the bladder never produces it. It resembles in appearance a gastric ulcer and probably has a somewhat similar etiology.

I have observed two cases, the histories of which are as follows:

CASE 1.-A man, aged 54, previous health excellent; had a mild attack of gonorrhea 8 years ago, no complications.

Prosent Illness.-For eight months he has suffered from a slightly increased frequency of micturition, attended by burning and discomfort. Very frequently during the day, independently of micturition, he has felt an uneasy painful sensation deep in the perineum. At the present time he urinates every two or three hours during the day and oecasionally at night; the pain and burning during urination have increased and the local discomfort has become greater, occasionally being felt for days at a time. He describes it now as a burning or tiekling sensation which is felt mainly in the dependent urethra. Other than this there is Lo disturbance.

Examination-Large, well-built, well-developed man. Heart and lungs negative; abdominal organs negative; external genitalia normal. No material can be expressed from the meatus on pressure; the prostate gland or palpation is prac. tically normal; the seminal vesicles are normal.

Urinalysis.-Pale straw color, slightly turbid; a number of fine granular particles and small shreds; acid; specific gravity 1.020 ; no albumin, no sugar. Microscopic examination showed numerous pus cells, some bladder epithelium, no casts, a few bacilli and cocci, no tubercle bacilli.
Cystoscopic Examination.-Endoscopic examination disclosed a normal urethra. With the cystoscope there was found a small round ulcer on the left lateral wall of the bladder about $2 \mathrm{~cm}$. behind the orifice of the left ureter. It was sharply punched out; the immediate edges were smooth and regular; the base was made up of a red, fairly firm-looking, granulation tissue, over which was a thin coating of a fibrinous exudate. The ulcer extends to the submucous tissue, but not beyond it. The adjacent mucous membrane was slightly injected, but otherwise presented no change. The remaining mucosa was entirely normal; there was not, the slightest evidence of a tuberculous process. The ureteral orifices looked healthy and emitted a clear urine. The capacity of the bladder was normal.

Treatment.-The patient was put on nitrate of silver irrigations, 1 to 10,000 , twice a week. His condition is improving.

In the following case the patient was seen in consultation only once and probably presented an example of a simple ulcer which was well advanced toward healing.

CASE 2.-Male, aged 27; previous history, except for a remote attack of gonorrhea, entirely negative. Three years ago the patient began to notice blood in the urine occasionally, and later suffered from inereased frequency in micturition and some pain. At the same time he had some discomfort and a burning sensation in the perineal and suprapubic regions. These symptoms gradually became worse and the bleeding more pronounced. During the last six months micturition has been compulsory every two or three hours during the day and from three to four hours during the night, although in the last two or three months this symptom has begun to improve and the bleeding is less frequent. The general health has not suffered.

Examination.-The patient has the appearance of being in excellent health. Heart, lungs and abdominal organs negative. Prostate and urethra negative.

Urinalysis.-Pale lemon, slightly clouded urine; acid, specific gravity 1.018; no albumin, no sugar. Microscopic examination showed leucocytes, some mucus and bladder epithelium.

Cystoscopic Examination.-On the right side of the lateral surface of the bladder, slightly behind the ureteral orifice, there was an irregular, ulcerated surface about the size of a ten-cent piece; the edges formed a somewhat irregular outline and extended here and there as fine projections into the ulcer. The edge in the main was smooth and sloped gradually to the granulating surface, so that it might be said to be almost on a level with it. It was of a bluish color, and appeared to be covered by an overgrowing epithelium. The base was sinooth; in spots here and there the granulation tissue projected above the surface. In other words, the ulcer presented the ordinary pieture seen in a healing process. The remaining mucous membrane was slightly injected but otherwise appeared to be normal.

While the above case may not be an example of a simple ulcer, I found no evidence of the ordinary causes (tuberculosis, for example) to explain its presence. The patient had been using and continued to use silver nitrate irrigations. Some months later he wrote that he was well.

Simple ulcer of the bladder has been very carefully observed and described by Fenwick, te Fur, Castaigne and others.

\section{PATHOLOGY.}

Two types are described: 1, The simple, chronic and solitary ulcer; 2 , the acute, perforating ulcer. The first type is usually found as a single ulcer, situated, as a rule, on the posterior wall of the bladder. It varies in size from $2 \mathrm{~mm}$. to $3 \mathrm{~cm}$. in diameter. It is usually circular with clean-cut edges. The base is covered with a red, not exuberant, granulation tissue over which there are scattered small particles of fibrin. The edges are only slightly indurated, and the immediately surround- 